\title{
An oral lipidic native testosterone formulation that is absorbed independent of food
}

\section{John Newell-Price', Hiep Huatan², Jo Quirke², John Porter², Eleni Daniel' ${ }^{1}$, Enis Mumdzic ${ }^{3}$, Bernard Voet $^{2}$, Brian Keevili ${ }^{4}$, Martin J Whitaker ${ }^{2}$ and Richard J Ross ${ }^{1}$}

${ }^{1}$ Department of Oncology and Metabolism, University of Sheffield, Sheffield, UK, ${ }^{2}$ Diurnal Ltd, Cardiff, UK, ${ }^{3}$ Sheffield Teaching Hospital, Sheffield, UK, and ${ }^{4}$ Department of Clinical Biochemistry, Wythenshawe Hospital, Manchester University NHS Foundation Trust, Manchester, UK

Correspondence should be addressed to R J Ross Email

R.J.Ross@sheffield.ac.uk

\section{Abstract}

Context: There is no licensed oral native testosterone (NT) because of challenges in the formulation. Licensed oral formulations of the ester, testosterone undecanoate (TU), require a meal for absorption and generate supraphysiological dihydrotestosterone (DHT) levels.

Objective: To develop an oral NT formulation.

Design and methods: A lipid-based formulation of native testosterone filled into soft-gelatin capsules at $40 \mathrm{mg}$ per capsule was designed with 2 years of stability at ambient temperature. Pharmacokinetic comparison studies of this oral lipidic NT formulation to oral TU were conducted in dogs and hypogonadal men.

Results: In dogs, 40 mg NT was well absorbed under fasted conditions whereas $40 \mathrm{mg}$ TU required a high-fat meal: for NT, the mean fed/fasted AUC ratio was 1.63 and for TU 7.05. In hypogonadal men, fed and fasted NT had similar pharmacokinetics: $C_{\max }$ mean 26.5 vs $30.4 \mathrm{nmol} / \mathrm{L}$ (769 vs $882 \mathrm{ng} / \mathrm{dL}$ ), $A \cup C_{0-10 \mathrm{~h}} 87 \mathrm{vs} 88.6 \mathrm{~h} \mathrm{nmol} / \mathrm{L}$. NT (fed state) showed a testosterone AUC increase of $45 \%$ between 120 and $200 \mathrm{mg}$, and NT $200 \mathrm{mg}$ gave a similar mean AUC $\mathrm{C}_{0-10 \mathrm{~h}}$ to TU $80 \mathrm{mg}: 87$ vs $64.8 \mathrm{~h} \mathrm{nmol} / \mathrm{L}$. Serum TU levels were variable and on a molar basis were $\sim$ ten-fold higher than serum testosterone levels after TU $80 \mathrm{mg}$ fed. The DHT: testosterone $\mathrm{AUC}_{0-10 \mathrm{~h}}$ ratio was more physiological for NT than TU being 0.19 vs 0.36 . There were no emerging safety concerns with NT.

Conclusion: This novel oral lipidic native testosterone formulation has potential advantages over oral TU of dosing independently of food and a lower risk of supraphysiological DHT levels.

\section{Significance statement}

There is no licensed oral testosterone because of challenges in formulation, and the oral formulations of the ester, testosterone undecanoate, require a fatty meal for absorption and generate supraphysiological dihydrotestosterone levels. We have overcome the design challenges and formulated an oral native testosterone that can be taken with or without food and provides physiological levels of testosterone and dihydrotestosterone in hypogonadal men. This formulation, DITEST, has the potential advantage of being oral for patients who do not tolerate injections and less risk of adverse events that might theoretically be associated with elevated dihydrotestosterone levels. Future studies will need to define the dosing regimen for replacement in hypogonadal men.

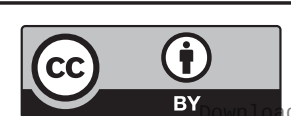

This work is licensed under a Creative Commons Attribution 4.0 International License. 


\section{Introduction}

Testosterone was isolated, named, and synthesized in 1935 (1), but to date, no oral native testosterone has been licensed for testosterone replacement therapy. The reason being that oral native testosterone, although absorbed through the intestine, undergoes extensive pre-systemic metabolism along the gastrointestinal tract (2), as well as rapid first-pass metabolism in the liver (3). The oral absorption of testosterone is also dependent on the dosing vehicle, wherein a lipophilic vehicle may increase the proportion of testosterone absorbed via the lymphatic route (4). It is thus difficult to achieve adequate bioavailability of testosterone in order to maintain consistent physiological testosterone levels via the oral route. To address this, different routes of administration for testosterone have been used and native testosterone replacement therapy has been licensed as implants, transdermal, transbuccal, and intranasal therapies (5).

Oral $17 \alpha$-alkylated androgens such as methyltestosterone and oxymetholone were proved to be effective androgen replacement therapies but were associated with severe liver damage including the development of jaundice, peliosis hepatis, and liver tumours (6). This toxic effect on the liver appears to be specific to oral modified (i.e. non-native) testosterones, particularly methylated testosterone and was not seen with native testosterone in animal models assessing liver toxicity (7). Testosterone undecanoate (TU) is an ester prodrug of testosterone and has a mid-chain length fatty acid at the $17 \beta$ position and when given orally undergoes absorption in part through the intestinal lymphatic pathway, so circumventing some of the first-pass metabolism through the liver (4). Oral testosterone undecanoate is presented as an oily capsule and has been available in Europe since the 1970s(1); however, TUhastobetaken with a meal two or three times daily, has an unpredictable absorption pattern, and generates high dihydrotestosterone (DHT) to testosterone ratio $(8,9,10)$. An oral self-emulsifying formulation of TU has recently been approved in the US (Jatenzo ${ }^{\circ}$, Clarus Therapeutics Inc., USA). The formulation promotes solubilization and intestinal lymphatic absorption of the lipophilic testosterone ester. Deesterification of TU by nonspecific esterases in liver, blood, and tissue results in the production of testosterone. The liberated undecanoic acid moiety is metabolized via beta-oxidation. 5-Alpha reduction of testosterone undecanoate in the gut produces dihydrotestosterone undecanoate (DHTU) and DHT (11). The testosterone undecanoate formulation has to be taken with food, patients have higher than normal DHT levels on treatment and the label is associated with a black box warning regarding an increase in blood pressure (12). These data support the need for new developments in this area.

Various oral formulations of native testosterone have been tested in man although none have been licensed $(13,14,15,16,17,18,19,20)$. Soon after testosterone's identification and characterization, oral testosterone administration was disregarded as a viable route of administration and replacement because of poor oral absorption (21). In the 1970s, a micronized form of free testosterone was demonstrated to be absorbed in hypogonadal men but absorption was not reliable enough to progress as therapy (14). Further research, particularly by Amory and coworkers, showed that native testosterone administered as a suspension in oil provided potentially therapeutic levels of testosterone in healthy men (15) and combined with $5 \alpha$-reductase inhibitors provided physiological testosterone levels both in the fasted and fed state (16). Native testosterone is practically insoluble in water and in fatty oil vehicles (22), and the challenge has been to develop a solution formulation that contains sufficient testosterone concentration to provide reproducible physiological testosterone levels in hypogonadal men. Building upon the previous observations, we have developed a lipidic solution formulation of native testosterone and have tested it in dogs and humans in the fasted and fed state.

\section{Subjects and methods}

\section{Formulation}

Lipidic native testosterone (NT) formulations were developed and assessed in vitro for dispersion behaviour in gastric and intestinal media and for physical stability. A single formulation of NT, DITEST, was selected to take forward into preclinical trials (Table 1). The formulation used digestible lipids (oils with carbon chain length $>10$ carbons atoms) with the addition of short-medium chain oils and ethanol as a polar co-solvent to assist with solubilization. The formulation was encapsulated in size 00 soft gelatin capsules with $40 \mathrm{mg}$ per capsule inside an aluminium foil blister pack and was stable for 2 years at ambient temperature $\left(25^{\circ} \mathrm{C}\right)$.

\section{Pharmacokinetics in dogs}

Female beagle dogs $(n=4)$ received a single oral administration on five separate occasions of either $40 \mathrm{mg}$ 
Table 1 Oral lipidic native testosterone formulation (DITEST).

\begin{tabular}{lll}
\hline Ingredient & & Grade \\
\cline { 1 - 1 } Testosterone & & Ph. Eur. \\
Sesame oil & Ph. Eur. \\
Propylene glycol monolaurate & Ph. Eur. \\
Benzyl alcohol & Ph. Eur. \\
Ethanol & Ph. Eur. \\
Gelatin & Ph. Eur. \\
\hline
\end{tabular}

\begin{tabular}{c}
\hline Quantity, \% (w/w) \\
\hline 5.43 \\
41.39 \\
31.62 \\
16.29 \\
5.27 \\
- \\
\hline
\end{tabular}

\begin{tabular}{c}
\hline Quantity per capsule (mg) \\
\hline 40.0 \\
305.0 \\
233.0 \\
120.0 \\
38.83 \\
-
\end{tabular}

\begin{tabular}{l} 
Function \\
\hline Active ingredient \\
Carrier \\
Surfactant \\
Solvent \\
Solvent \\
Capsule shell
\end{tabular}

NT capsules or $40 \mathrm{mg}$ TU (Andriol ${ }^{\circ}$ Testocaps, MSD, UK) in the fed and fasted state or NT capsules $80 \mathrm{mg}$ fed. Blood samples were taken at $0.5,1,2,3,4,6,10,12$, and $24 \mathrm{~h}$ following each dose administration.

\section{Pharmacokinetics in hypogonadal men}

A single-centre, phase $1 \mathrm{~b}$ study to compare the pharmacokinetics of NT 120 and $200 \mathrm{mg}$ with TU $80 \mathrm{mg}$ (Andriol ${ }^{\circ}$ Testocaps, MSD, UK) in adult male participants with primary or secondary hypogonadism (EUDRACT: 2015-004255-46). A higher dose of NT to TU was chosen as NT and was expected to have reduced bioavailability compared to TU based on the preclinical dog studies. Key inclusion criteria were male aged 18-80 years; diagnosis of primary testicular failure or secondary hypogonadism due to known pituitary disease or congenital deficit; BMI $>18$ $\mathrm{kg} / \mathrm{m}^{2}$ and $<35 \mathrm{~kg} / \mathrm{m}^{2}$; testosterone level $<8 \mathrm{nmol} / \mathrm{L}(232$ $\mathrm{ng} / \mathrm{dL}$ ) after washout of current testosterone treatment and normal prostate-specific antigen (PSA). Exclusion criteria included history of cancer, myocardial infarction, or unstable cardiovascular disease, and haematocrit levels > $0.5 \mathrm{~L} / \mathrm{L}(50 \%)$ at baseline.

The primary objective was to compare the rate and extent of absorption of testosterone from a single dose of NT with a single dose of $80 \mathrm{mg}$ TU in the fed state following the standard FDA high-fat, high-calorie meal defined as an $800-1000$ calorie meal where approximately $50 \%$ of total caloric content comes from fat (23). The secondary objectives were to assess the impact of food on the rate and extent of absorption of testosterone from NT and the safety and tolerability of two different doses of NT. The exploratory objectives included assessing the levels of DHT in serum. The study was a randomized, active control, single-dose, two-way crossover study in two cohorts. In each cohort, participants were randomized to one of two treatments with treatments separated by a minimum 7-day washout:

Cohort 1: in the fed state with a high-fat meal either a single dose of $120 \mathrm{mg}(3 \times 40 \mathrm{mg})$ NT followed by a single dose of $80 \mathrm{mg}(2 \times 40 \mathrm{mg}) \mathrm{TU}$ or a single dose of $80 \mathrm{mg}(2 \times 40 \mathrm{mg})$ TU followed by a single dose of $120 \mathrm{mg}(3 \times 40 \mathrm{mg}) \mathrm{NT}$.
Cohort 2: a single dose of $200 \mathrm{mg}(5 \times 40 \mathrm{mg})$ NT (fed with a high-fat meal) followed by a single dose of $200 \mathrm{mg}$ $(5 \times 40 \mathrm{mg})$ NT (fasted) or a single dose of $200 \mathrm{mg}$ $(5 \times 40 \mathrm{mg}) \mathrm{NT}$ (fasted) followed by a single dose of $200 \mathrm{mg}(5 \times 40 \mathrm{mg})$ NT (fed with a high-fat meal).

On each dosing day, samples were taken at $-0.5,-0.25$ (cohort 1 only), $0,0.5,1$, 1.5, 2, 2.5, 3, 3.5, 4, 4.5, 5, 5.5, 6, 7, 8 , and $10 \mathrm{~h}$ for pharmacokinetic (PK) assessment. There was a minimum of 3 months separation between treatments in cohorts 1 and 2 .

\section{Assays}

Liquid chromatography with tandem mass spectrometry (LC-MS/MS) analysis for serum testosterone and DHT was performed using a Waters Xevo TQ-S ${ }^{\mathrm{TM}}$ mass spectrometer and a Waters Acquity ${ }^{\mathrm{TM}} \mathrm{LC}$ system with an electrospray source operated in positive ionization mode. For testosterone, the lower limit of quantitation (LLOQ) was $0.1 \mathrm{nmol} / \mathrm{L}$ and the assay was linear up to $40 \mathrm{nmol} / \mathrm{L}$. The inter-assay imprecision was $3.9,3.9$, and $3.1 \%$ at concentrations of $0.5,4.7$, and 14.0 $\mathrm{nmol} / \mathrm{L}$, respectively. The reference range for adult men aged $18-39$ years is $9.2-31.8 \mathrm{nmol} / \mathrm{L}$ (24). For DHT, the LLOQ was $0.3 \mathrm{nmol} / \mathrm{L}$, and the assay was linear up to $50 \mathrm{nmol} / \mathrm{L}$. The inter-assay imprecision was $11.2,8.4$, and $5.8 \%$ at concentrations of $0.3,0.9$, and $8.3 \mathrm{nmol} / \mathrm{L}$, respectively. The reference range for adult men aged $<65$ is $0.8-3.5 \mathrm{nmol} / \mathrm{L}$ (25). LC-MS/MS analysis for serum testosterone undecanoate was performed using a Waters Xevo TQ-S Micro ${ }^{\mathrm{TM}}$ mass spectrometer and a Waters Acquity ${ }^{\mathrm{TM}} \mathrm{LC}$ system with an electrospray source operated in positive ionization mode. For TU, the LLOQ was $0.002 \mathrm{nmol} / \mathrm{L}(1.0 \mathrm{ng} / \mathrm{L})$, and the assay was linear up to $4.38 \mathrm{nmol} / \mathrm{L}(2000 \mathrm{ng} / \mathrm{L})$. The interassay imprecision was $11.2,8.4$, and $5.2 \%$ at concentrations of $0.02,0.18$, and $1.53 \mathrm{nmol} / \mathrm{L}(8.0,80$, and $700 \mathrm{ng} / \mathrm{L})$, respectively. All LCMS instruments are calibrated monthly.

\section{Statistics in hypogonadal men}

PK parameters $\left(\mathrm{C}_{\max }\right.$ and $\left.\mathrm{AUC}\right)$ were calculated based on actual sampling times with correction for baseline 
testosterone that is, by subtraction of the mean of individual pre-dose concentrations. In each cohort, the primary PK endpoints were analysed using an ANOVA model corresponding to a two-way crossover design with fixed effects for sequence, treatment, period, and participant nested within the sequence. The comparison between NT $200 \mathrm{mg}$ and TU $80 \mathrm{mg}$ in the fed state was based on the ANOVA model with treatment as the only fixed effect. The analyses were based on the log-transformed concentrations. The $90 \%$ CIs for the ratio of the treatment effects were calculated using the mean square error from the ANOVA models. PK parameters ( $\mathrm{C}_{\max }$ and AUC) from the non-compartmental analysis were cross-correlated with body weight.

\section{Ethics}

The study protocol was approved by the North West Greater Manchester South Research Ethics Committee (Reference number: 16/NW/0242: 193020) and the Medicines and Healthcare Products Regulatory Agency (MHRA), UK. The trial was performed in accordance with the ethical principles that have their origins in the Declaration of Helsinki (October 2013) and in accordance with International Conference for Harmonisation Good Clinical Practice (ICH GCP) with all subjects providing written informed consent.

\section{Results}

\section{Pharmacokinetics in dogs}

Baseline corrected quantifiable testosterone concentrations were reported in all animals $(n=4)$ on all dosing occasions up to at least $4 \mathrm{~h}$ after dosing with NT and TU. For NT, systemic exposure of testosterone approximately doubled following an increase in the administered dose from 40 to $80 \mathrm{mg}$ fed, suggesting dose proportionality. TU was poorly absorbed when fasted: geometric mean AUC $\mathrm{h} \mathrm{ng} / \mathrm{mL}$ fasted vs fed 10.7 vs 64.6 whereas NT was absorbed fasted with less difference between geometric mean AUC fasted vs fed $15.4 \mathrm{~h} \mathrm{ng} / \mathrm{mL}$ vs $25.5 \mathrm{~h} \mathrm{ng} / \mathrm{mL}$ (Table 2$)$. The ratio (90\% CI) fed: fasted for AUC was 1.63 (1.19-2.07) for NT vs 7.05 (5.79-8.31) for TU.

\section{Demographics of hypogonadal men}

A total of 30 participants were screened, with 8 participants failing screening and not taking part in the study (Fig. 1). The reasons for screen failure were testosterone level $>8 \mathrm{nmol} / \mathrm{L}(232 \mathrm{ng} / \mathrm{dL})(n=5)$, haematocrit $>0.5$ $(n=1), \mathrm{BMI}>35 \mathrm{~kg} / \mathrm{m}^{2}(n=1)$ and unable to consume the standard high-fat breakfast $(n=1)$. A total of 22 participants were enrolled in the study (in either cohort 1 , cohort 2 , or both cohorts) and received at least one study intervention. Three participants were enrolled in both cohorts since participants from cohort 1 could be entered into cohort 2 after a washout period of at least 3 months between cohorts. For the purposes of the analysis, these three participants were handled as separate participants in each cohort so a total of 25 individual cases were randomized and treated during the study (Fig. 1). In the overall safety set $(n=25)$, participants had a mean (S.D.): age of 53.8 (13.9) years; body weight of 91.7 (13.0) kg; BMI of 29.1 (3.7) kg/m². Most participants were white $(92.0 \%)$. Mean \pm S.D. baseline serum testosterone was $3 \pm 2.6 \mathrm{nmol} / \mathrm{L}(87 \pm 75 \mathrm{ng} / \mathrm{dL})$ (Table 3 ). One participant in cohort 1 was withdrawn early from the study because he started a prohibited medication during the washout between treatment periods. This participant only received the study intervention in period 1 (TU) and was replaced. Twelve participants completed the study in each cohort.

\section{Pharmacokinetics in hypogonadal men}

Cohort 1, comparing $120 \mathrm{mg}$ NT with $80 \mathrm{mg}$ TU taken in the fed state with a high-fat meal showed both formulations generated testosterone levels in the physiological range and $80 \mathrm{mg}$ TU gave higher testosterone levels than $120 \mathrm{mg}$ NT (Fig. 2). NT had an earlier $\mathrm{T}_{\max }$ than TU: $1.4 \mathrm{vs} 4.2 \mathrm{~h}$ (Table 4). NT resulted in around 50\% lower levels of DHT than TU,

Table 2 Pharmacokinetic parameters for NT and TU in dogs.

\begin{tabular}{|c|c|c|}
\hline Formulation & Testosterone dose (mg) & Fasted or fed \\
\hline NT & 40 & Fasted \\
\hline NT & 40 & Fed \\
\hline NT & 80 & Fed \\
\hline TU & 40 & Fasted \\
\hline TU & 40 & Fed \\
\hline
\end{tabular}

\begin{tabular}{c}
\hline $\mathbf{T}_{\max (\mathrm{obs})}(\mathrm{h}) *$ \\
\hline $0.50(0.50,1.00)$ \\
$0.50(0.50,0.50)$ \\
$1.00(1.00,3.00)$ \\
$1.50(1.00,10.0)$ \\
$2.00(1.00,10.0)$
\end{tabular}

\begin{tabular}{c}
$\mathbf{C}_{\max (\mathrm{obs})}(\mathrm{ng} / \mathrm{mL})^{\dagger}$ \\
\hline $7.98(32.9)$ \\
$11.0(35.3)$ \\
$18.7(38.1)$ \\
$1.78(45.3)$ \\
$18.0(83.8)$ \\
\hline
\end{tabular}

\begin{tabular}{c} 
AUC $_{\mathbf{0 - t}}(\mathrm{h} \mathrm{ng/mL})^{\dagger}$ \\
\hline $15.4(16.6)$ \\
$25.5(26.8)$ \\
$63.3(20.6)$ \\
$10.7(25.4)$ \\
$64.6(20.0)$
\end{tabular}

*Values are median (range); ${ }^{\dagger}$ Values are geometric mean (CV\%). 


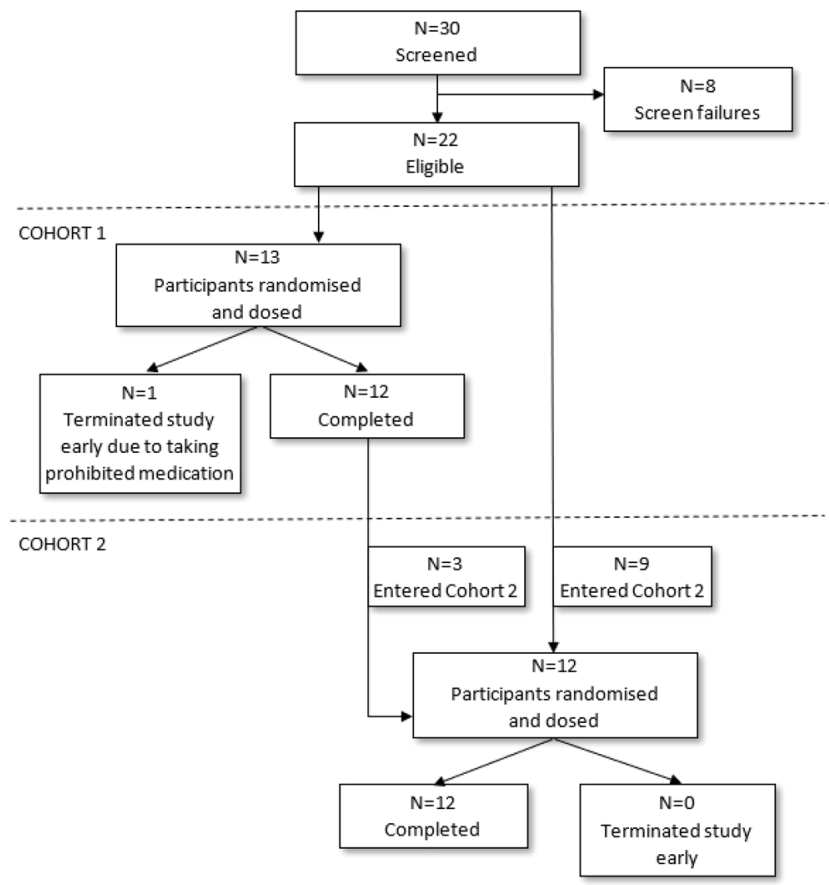

\section{Figure 1}

CONSORT diagram, disposition of participants.

and the ratio of DHT: $\mathrm{T}$ for $\mathrm{AUC}_{0-10 \mathrm{~h}}$ for NT was 0.19 and for TU 0.36. Serum TU levels after dosing with $80 \mathrm{mg}$ TU were approximately ten-fold greater than serum testosterone levels on a molar basis and showed considerable variability between subjects (Fig. 3).

Cohort 2, NT $200 \mathrm{mg}$ given either fed with a highfat meal or fasted showed similar testosterone levels and pharmacokinetics (Fig. 4). Comparing levels in cohort 2 to cohort 1 , NT showed a serum testosterone AUC increase of $45 \%$ between 120 and $200 \mathrm{mg}$. NT $200 \mathrm{mg}$ fasted gave equivalent $\mathrm{C}_{\max }$ and $\mathrm{AUC}_{0-10 \mathrm{~h}}$ to TU $80 \mathrm{mg}$ fed: $90 \%$ CIs 88.0 (58.2-133.1) and 87.5 (54.6-140.2).

Cross correlation of the $\mathrm{PK}$ parameters $\mathrm{C}_{\max }$ and $\mathrm{AUC}_{\text {inf }}$ for serum testosterone levels after NT using all doses showed weak negative correlation with body weight: $r$ of -0.45 and -0.27 , respectively.

There was one serious adverse event (urinary retention) during TU dosing. There were no emerging safety concerns, and adverse event frequency and severity were similar between the different treatment arms.

\section{Discussion}

We have developed an oral lipidic formulation of native testosterone in a solution that provides physiological levels of testosterone and DHT when taken with or without food.

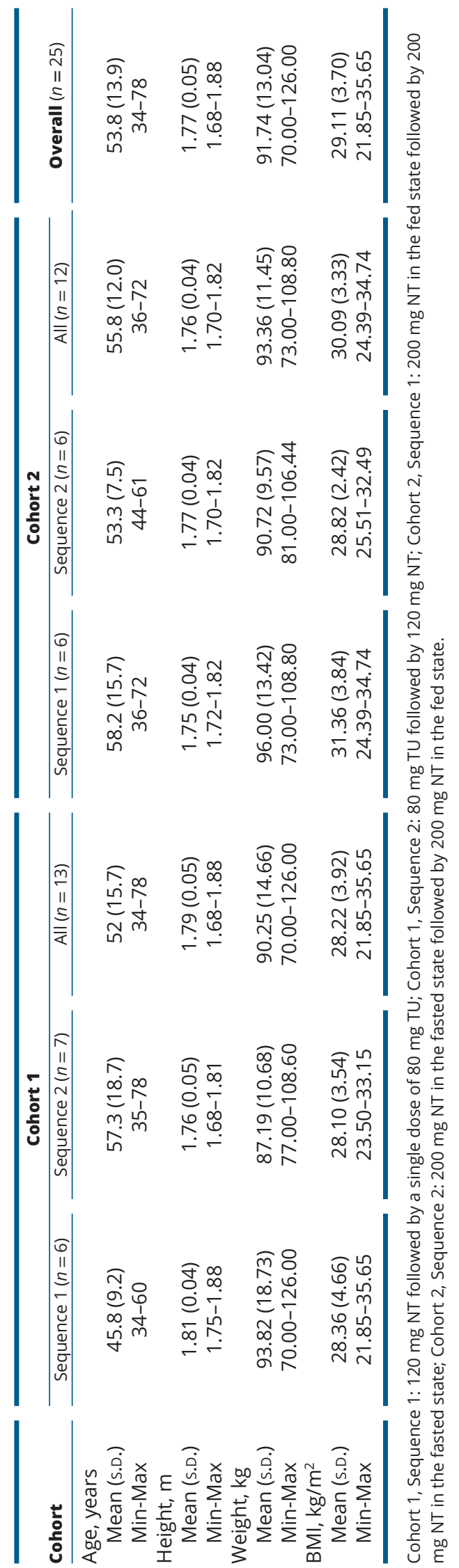

https://eje.bioscientifica.com 

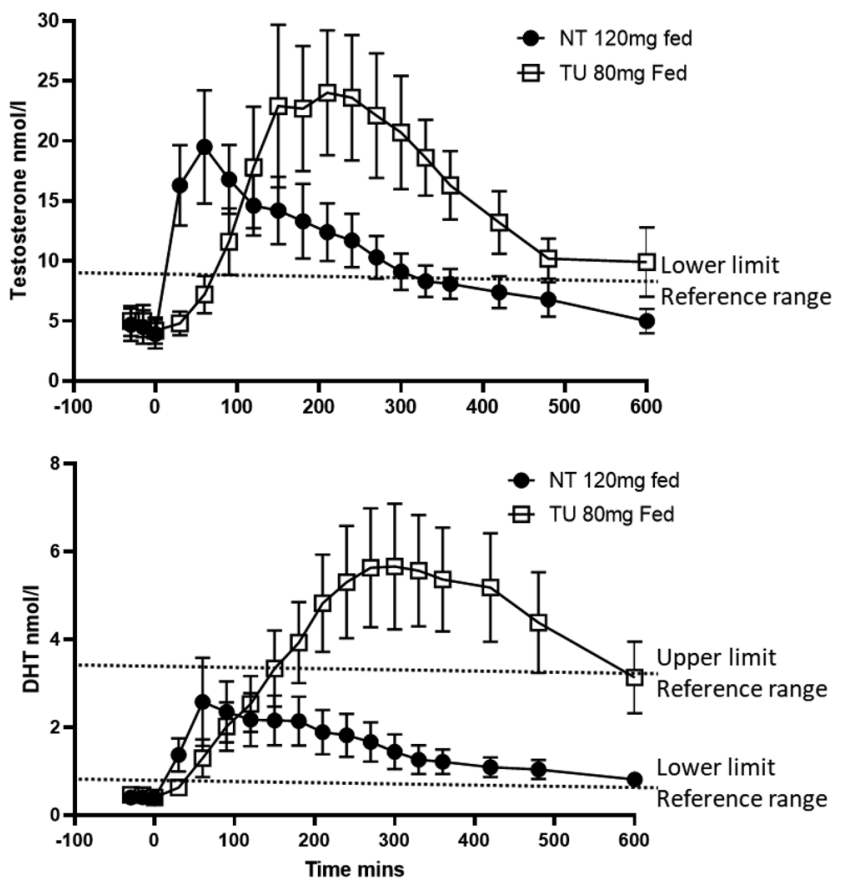

Figure 2

Mean (S.E.M.) serum testosterone and DHT levels following NT $120 \mathrm{mg}$ and TU $80 \mathrm{mg}$.

The preclinical study in dogs showed that the oral lipidic NT formulation showed less variability in absorption between the fasted and fed state compared to $\mathrm{TU}$ and that very little TU was absorbed in the fasted state, confirming previous results in the literature (26). The results for the NT formulation were confirmed in hypogonadal men where the NT formulation showed similar pharmacokinetics when taken fasted or fed and the ratio of DHT to testosterone was lower for NT than TU.

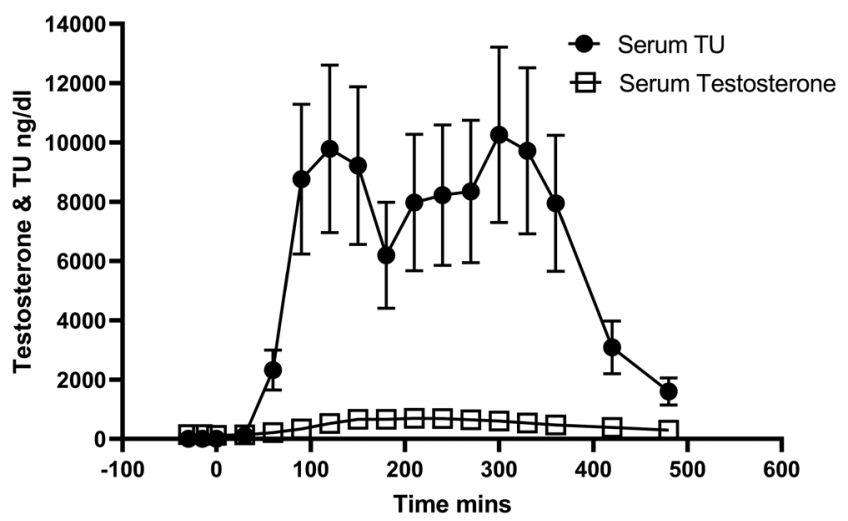

Figure 3

Mean (S.E.M.) serum TU and testosterone levels after TU $80 \mathrm{mg}$ fed.
It is known that native testosterone is absorbed orally but because of the extensive pre-systemic metabolism in the gastrointestinal tract and rapid firstpass metabolism in the liver, a high dose is required to replace physiological circulating serum testosterone levels (1). This is compounded by the fact that testosterone is practically insoluble in water and fatty acid oils (22), so it has been challenging to generate a solution formulation of testosterone with a testosterone concentration sufficient to replace circulating testosterone levels. We have addressed this by generating a lipidic solution formulation where testosterone is held in solution in the oil phase through the addition of co-solvents: ethanol and benzyl alcohol. The formulation is stable at room temperature for up to 2 years and provides reproducible physiological testosterone levels in hypogonadal men.

TU, an ester prodrug of testosterone, given orally, undergoes absorption through the intestinal lymphatic pathway and thus circumvents first-pass metabolism through the liver. The $\mathrm{T}_{\max }$ for NT was earlier than TU in both the dog and hypogonadal men reflecting that the NT formulation is likely primarily absorbed via the intestinal transcellular route through the hepatic portal circulation. In the fed state, TU provided higher levels of circulating testosterone per unit dose of testosterone than NT; however, the TU levels of the prodrug in the circulation were $\sim$ ten-fold greater than serum testosterone levels on a molar basis and showed great variation. This result is similar to the $\sim$ ten-fold greater levels of $\mathrm{TU}$ prodrug than total testosterone previously reported for TU (11), suggesting that, although TU is well absorbed, a relatively low fraction is converted to testosterone and most of that conversion probably takes place in the gut at the time of absorption as does the generation of DHT. The FDA-approved TU formulation, Jatenzo ${ }^{\circ}$, recommends a starting dose of $237 \mathrm{mg}$ ( $150 \mathrm{mg}$ of unesterified testosterone equivalents based on molecular weight) and a maximum dose of $396 \mathrm{mg}$ (250 mg testosterone equivalents) twice daily (12). These are similar to the dosing levels of the NT formulation used in the phase $1 \mathrm{~b}$ study, 120 to $200 \mathrm{mg}$, that provided a physiological testosterone concentration. The recommended starting dose of the European approved TU formulation, Andriol', is $120-160 \mathrm{mg}$ (75-100 mg testosterone) daily and in our study, we found higher testosterone levels after $80 \mathrm{mg}$ Andriol ${ }^{\circ}$ taken with a highfat meal than after NT $120 \mathrm{mg}$. The difference in apparent bioavailability of the different TU formulations may relate to the fat content of the meal in studies or the formulation.

$\mathrm{TU}$ requires a fat-containing meal for absorption $(8,9$, 10), as illustrated here by very low circulating testosterone 
Table 4 Pharmacokinetic summary of data comparing native testosterone (NT) with testosterone undecanoate (TU) and NT taken fasted and fed in hypogonadal men (baseline-adjusted pharmacokinetic set). Data are presented as mean (s.D.).

\begin{tabular}{|c|c|c|c|c|c|c|}
\hline & \multicolumn{3}{|c|}{ Cohort $1^{\dagger}$} & \multicolumn{3}{|c|}{ Cohort $2^{\ddagger}$} \\
\hline & DITEST $120 \mathrm{mg}$ & TU $80 \mathrm{mg}$ & GLSM ratio $(90 \% \mathrm{Cl})$ & Fed & Fasted & GLSM ratio $(90 \% \mathrm{Cl})$ \\
\hline \multicolumn{7}{|l|}{ Testosterone } \\
\hline \multicolumn{7}{|l|}{$\mathrm{C}_{\max }$} \\
\hline $\mathrm{ng} / \mathrm{dL}$ & $554(481)$ & $911(670)$ & $55.6(45-68.7)$ & $769(421)$ & $882(458)$ & $85.1(57.5-126.0)$ \\
\hline $\mathrm{nmol} / \mathrm{L}$ & $19.1(16.6)$ & $31.4(23.1)$ & & $26.5(14.5)$ & $30.4(15.8)$ & \\
\hline \multicolumn{7}{|l|}{$A \cup C_{0-10 h}$} \\
\hline h ng/dL & 1726 (1578) & $2958(2480)$ & $51.3(34.7-75.7)$ & $2523(1615)$ & 2569 (1496) & $94.2(66.1-134.2)$ \\
\hline h nmol/L & $59.5(54.4)$ & $102(85.5)$ & & 87.0 (55.7) & 88.6 (51.6) & \\
\hline $\mathrm{T}_{\max } \mathrm{h}$ & $1.4(1.0)$ & $4.2(2.1)$ & & $1.4(0.6)$ & $1.2(0.6)$ & \\
\hline \multicolumn{7}{|l|}{ TU } \\
\hline \multicolumn{7}{|l|}{$\mathrm{C}_{\max }$} \\
\hline $\mathrm{ng} / \mathrm{dL}$ & & $20900(8500)$ & & & & \\
\hline $\mathrm{nmol} / \mathrm{L}$ & & $458(186)$ & & & & \\
\hline \multicolumn{7}{|l|}{$\mathrm{AUC}_{0-10 \mathrm{~h}}$} \\
\hline h ng/dL & & $47200(18500)$ & & & & \\
\hline $\mathrm{h} \mathrm{nmol/L}$ & & 1034 (405) & & & & \\
\hline \multicolumn{7}{|l|}{$T_{\max } h$} \\
\hline DHT & & $3.8(2.3)$ & & & & \\
\hline \multicolumn{7}{|l|}{$\mathrm{C}_{\max }$} \\
\hline $\mathrm{ng} / \mathrm{dL}$ & $84(99)$ & 194 (119) & & $119(58)$ & $131(61)$ & \\
\hline $\mathrm{nmol} / \mathrm{L}$ & $2.9(3.4)$ & $6.7(4.1)$ & & $4.1(2.0)$ & $4.5(2.1)$ & \\
\hline \multicolumn{7}{|l|}{$A \cup C_{0-10 h}$} \\
\hline h ng/dL & $319(351)$ & $1053(850)$ & & 467 (270) & 484 (299) & \\
\hline $\mathrm{h} \mathrm{nmol} / \mathrm{L}$ & $11.0(12.1)$ & $36.3(29.3)$ & & $16.1(9.3)$ & $16.7(10.3)$ & \\
\hline $\mathrm{T}_{\max } \mathrm{h}$ & $2.4(2.1)$ & $5.7(1.9)$ & & $1.7(0.6)$ & $1.6(0.7)$ & \\
\hline
\end{tabular}

To convert testosterone $\mathrm{nmol} / \mathrm{L}$ to $\mathrm{ng} / \mathrm{dL}$ multiply by 29 ; To convert DHT nmol/L to ng/dL multiply by 29 ; To convert TU ug/L to ng/dL multiply by 100 ; To convert TU multiply ug/L by 2.19 to get nmol/L. ${ }^{\dagger} F e d ~ N T 120 \mathrm{mg}$ vs TU $80 \mathrm{mg} .{ }^{\ddagger} \mathrm{NT} 200 \mathrm{mg}$ fed vs fasted.

GLSM, geometric least squared mean.

levels in the dogs when TU was given fasted. Currently, there is only one marketed US Food and Drug Administration (FDA)-approved TU oral product, Jatenzo ${ }^{\circ}$, with potentially a second product available shortly, Tlando (Lipocine Inc., US), which has reported conditional approval from the FDA. Jatenzo ${ }^{\curvearrowleft}$ was poorly absorbed fasted, TU and DHTU concentrations were 6.2- and 8.8-fold higher, respectively, in the fed state (30\% fat meal) compared with fasting (11), and in the phase 3 study was administered twice daily with food (12). In contrast, we have demonstrated that native non-esterified testosterone absorption is not affected by food.

TU formulations that replace physiological testosterone levels generate supraphysiological levels of DHT (13), whereas NT formulations provide more physiological levels of DHT (20). The lipidic NT formulation reported here generated a more physiological ratio of DHT to total testosterone compared to TU. To date, there is no evidence that raised DHT levels are harmful, although theoretically there may be more impact on DHT responsive tissues such as skin and prostate. Reassuringly, however, the increased serum DHT concentrations resulting from therapy with oral testosterone undecanoate were not associated with an increased risk of prostate cancer or prostate enlargement in long-term studies (27). The impact of $17 \alpha$-alkylated androgens on liver toxicity has not been seen with NT formulations (20), and no change in liver function tests was seen in this single-dose study with the NT formulation. However, longer-term studies with NT are required to examine the impact on liver function. After NT dosing, there was a negative correlation between $\mathrm{PK}$ parameters suggesting that the greater the weight the lower the $\mathrm{C}_{\max }$ and AUC, but the correlation was weak and testosterone replacement is generally titrated according to serum testosterone levels in the individual rather than weight.

This manuscript reports clinical data from a singledose study in a cohort of hypogonadal men, and future studies will need to generate 24 -h pharmacokinetic data at a steady state for a range of dose levels. Consideration will also need to be given to increasing the dose per capsule, measuring SHBG levels, and investigating the potential need for dose titration in clinical practice. Testosterone may induce its own metabolism and so the impact of repeat dosing will need to be examined (14). 


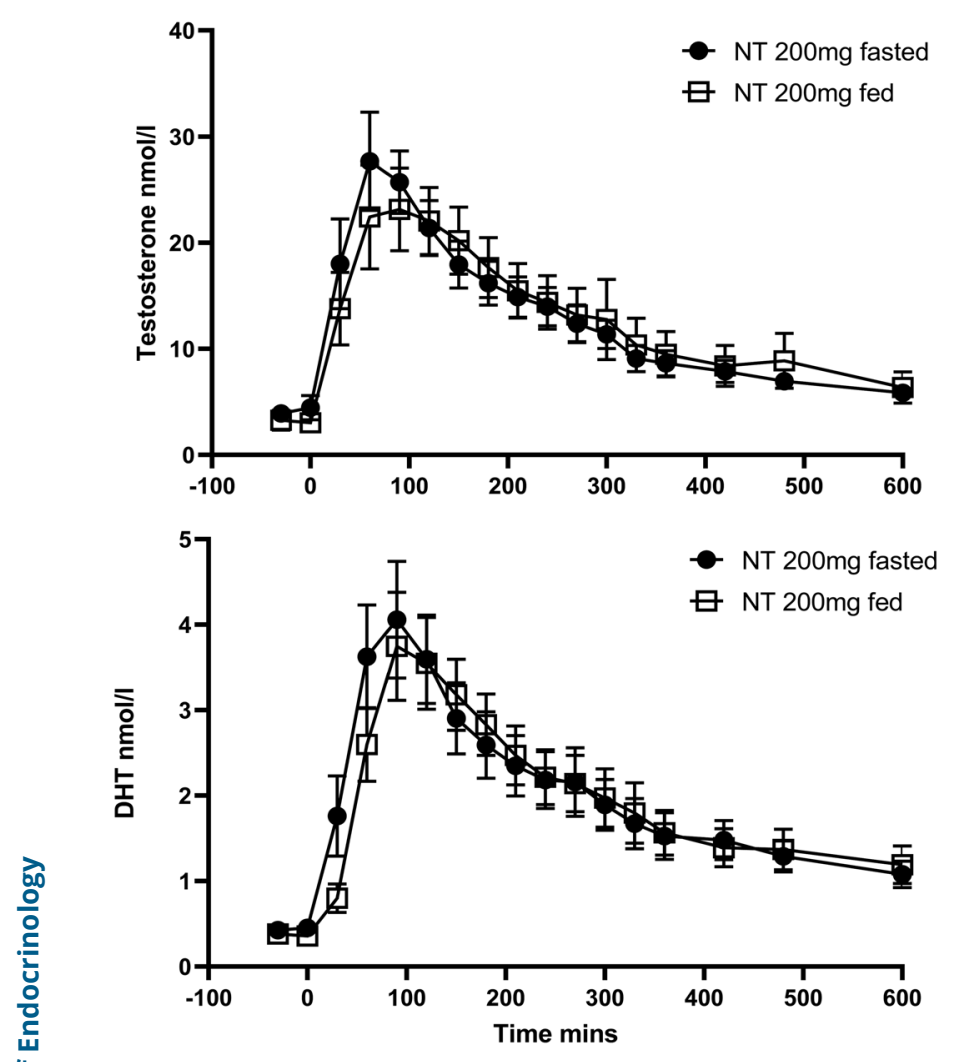

Figure 4

Mean (S.E.M.) serum testosterone and DHT levels following NT $200 \mathrm{mg}$ fasted and fed.

The levels of testosterone, DHT, and TU were quantified from serum samples, and following the start of the study in hypogonadal males it was recognized that TU can be converted to testosterone in serum ex vivo and, therefore, the testosterone levels measured after TU administration may be higher than they would have been if measured in plasma (28).

In conclusion, we have developed a lipidic NT formulation, which when given to hypogonadal men generates similar testosterone and DHT exposure in the fed and fasted state. Compared to published literature on a self-emulsifying formulation of TU at $200 \mathrm{mg}$ (12), the NT formulation at $200 \mathrm{mg}$ provides a similar testosterone $\mathrm{C}_{\max }$ and no requirement for a meal. This oral lipidic native testosterone formulation has anticipated advantages over current oral therapy of dosing with or without food and a lower risk of supraphysiological DHT levels.

\section{Declaration of interest}

J N P received research funds from Diurnal Ltd; R J R and $M J W$ are Directors; J P and J Q are employees and $\mathrm{H} \mathrm{H}$ and $\mathrm{B} \mathrm{V}$ are consultants of Diurnal Ltd.
Funding

This study was sponsored and funded by Diurnal Ltd. UK.

\section{Author contribution statement}

The first and last authors vouch for the accuracy, completeness of the data and analyses. All authors critically reviewed the manuscript. J N P, H H, J Q, JP, B V, M JW, R J R participated in the design and analysis of the trial. J N P, $E D, E M$ were responsible for recruitment and delivery of the trial. BK was responsible for hormone analysis.

\section{References}

1 Nieschlag E \& Nieschlag S. Testosterone deficiency: a historical perspective. Asian Journal of Andrology 201416 161-168. (https://doi. org/10.4103/1008-682X.122358)

2 Farthing MJ, Vinson GP, Edwards CR \& Dawson AM. Testosterone metabolism by the rat gastrointestinal tract, in vitro and in vivo. Gut 198223 226-234. (https://doi.org/10.1136/gut.23.3.226)

3 Pacifici GM, Gucci A \& Giuliani L. Testosterone sulphation and glucuronidation in the human liver: interindividual variability. European Journal of Drug Metabolism and Pharmacokinetics 199722 253-258. (https://doi.org/10.1007/BF03189815)

4 Shackleford DM, Faassen WA, Houwing N, Lass H, Edwards GA, Porter CJ \& Charman WN. Contribution of lymphatically transported testosterone undecanoate to the systemic exposure of testosterone after oral administration of two andriol formulations in conscious lymph duct-cannulated dogs. Journal of Pharmacology and Experimental Therapeutics 2003306 925-933. (https://doi.org/10.1124/ jpet.103.052522)

5 Bhasin S, Brito JP, Cunningham GR, Hayes FJ, Hodis HN, Matsumoto AM, Snyder PJ, Swerdloff RS, Wu FC \& Yialamas MA. Testosterone therapy in men with hypogonadism: an endocrine society clinical practice guideline. Journal of Clinical Endocrinology and Metabolism 2018103 1715-1744. (https://doi.org/10.1210/jc.201800229)

6 Westaby D, Ogle SJ, Paradinas FJ, Randell JB \& Murray-Lyon IM. Liver damage from long-term methyltestosterone. Lancet 19772 262-263. (https://doi.org/10.1016/S0140-6736(77)90949-7)

7 Hild SA, Attardi BJ, Koduri S, Till BA \& Reel JR. Effects of synthetic androgens on liver function using the rabbit as a model. Journal of Andrology 201031 472-481. (https://doi.org/10.2164/ jandrol.109.009365)

8 Schurmeyer T, Wickings EJ, Freischem CW \& Nieschlag E. Saliva and serum testosterone following oral testosterone undecanoate administration in normal and hypogonadal men. Acta Endocrinologica 1983102 456-462. (https://doi.org/10.1530/acta.0.1020456)

9 Bagchus WM, Hust R, Maris F, Schnabel PG \& Houwing NS. Important effect of food on the bioavailability of oral testosterone undecanoate. Pharmacotherapy 200323 319-325. (https://doi.org/10.1592/ phco.23.3.319.32104)

10 Bhasin S, Cunningham GR, Hayes FJ, Matsumoto AM, Snyder PJ, Swerdloff RS \& Montori VM. Testosterone therapy in adult men with androgen deficiency syndromes: an endocrine society clinical practice guideline. Journal of Clinical Endocrinology and Metabolism 200691 1995-2010. (https://doi.org/10.1210/jc.2005-2847)

11 Yin AY, Htun M, Swerdloff RS, Diaz-Arjonilla M, Dudley RE, Faulkner S, Bross R, Leung A, Baravarian S, Hull L et al. Reexamination of pharmacokinetics of oral testosterone undecanoate in hypogonadal men with a new self-emulsifying formulation. Journal of Andrology 201233 190-201. (https://doi.org/10.2164/jandrol.111.013169)

12 Swerdloff RS, Wang C, White WB, Kaminetsky J, Gittelman MC, Longstreth JA, Dudley RE \& Danoff TM. A new oral testosterone undecanoate formulation restores testosterone to normal concentrations 
in hypogonadal men. Journal of Clinical Endocrinology and Metabolism 2020105 2515-2531. (https://doi.org/10.1210/clinem/dgaa238)

13 Nieschlag E, Mauss J, Coert A \& Kicovic P. Plasma androgen levels in men after oral administration of testosterone or testosterone undecanoate. Acta Endocrinologica 197579 366-374. (https://doi. org/10.1530/acta.0.0790366)

14 Daggett PR, Wheeler MJ \& Nabarro JD. Oral testosterone, a reappraisal. Hormone Research 19789 121-129. (https://doi.org/10.1159/000178904)

15 Amory JK \& Bremner WJ. Oral testosterone in oil plus dutasteride in men: a pharmacokinetic study. Journal of Clinical Endocrinology and Metabolism 200590 2610-2617. (https://doi.org/10.1210/jc.2004-1221)

16 Amory JK, Page ST \& Bremner WJ. Oral testosterone in oil: pharmacokinetic effects of 5 alpha reduction by finasteride or dutasteride and food intake in men. Journal of Andrology 200627 72-78. (https://doi.org/10.2164/jandrol.05058)

17 Page ST, Bremner WJ, Clark RV, Bush MA, Zhi H, Caricofe RB, Smith PM \& Amory JK. Nanomilled oral testosterone plus dutasteride effectively normalizes serum testosterone in normal men with induced hypogonadism. Journal of Andrology 200829 222-227. (https://doi.org/10.2164/jandrol.107.002956)

18 Snyder CN, Clark RV, Caricofe RB, Bush MA, Roth MY, Page ST, Bremner WJ \& Amory JK. Pharmacokinetics of 2 novel formulations of modified-release oral testosterone alone and with finasteride in normal men with experimental hypogonadism. Journal of Andrology 201031 527-535. (https://doi.org/10.2164/jandrol.109.009746)

19 Amory JK, Bush MA, Zhi H, Caricofe RB, Matsumoto AM, Swerdloff RS, Wang C \& Clark RV. Oral testosterone with and without concomitant inhibition of 5alpha-reductase by dutasteride in hypogonadal men for 28 days. Journal of Urology 2011185 626-632. (https://doi. org/10.1016/j.juro.2010.09.089)

20 Lee A, Rubinow K, Clark RV, Caricofe RB, Bush MA, Zhi H, Roth MY, Page ST, Bremner WJ \& Amory JK. Pharmacokinetics of modified slow- release oral testosterone over 9 days in normal men with experimental hypogonadism. Journal of Andrology 201233 420-426. (https://doi. org/10.2164/jandrol.111.014514)

21 Foss GL. Clinical administration of androgens. Lancet 1939233 502-504. (https://doi.org/10.1016/S0140-6736(00)74069-4)

22 Pharmacopeia E. European Directorate for the Quality of Medicines 2019 10th Edition 10.2.

23 FDA. Food-effect bioavailability and fed bioequivalence studies. In Guidance for Industry. U.S. Department of Health and Human Services Food and Drug Administration Center for Drug Evaluation and Research, 2002.

24 Travison TG, Vesper HW, Orwoll E, Wu F, Kaufman JM, Wang Y, Lapauw B, Fiers T, Matsumoto AM \& Bhasin S. Harmonized reference ranges for circulating testosterone levels in men of four cohort studies in the United States and Europe. Journal of Clinical Endocrinology and Metabolism 2017102 1161-1173. (https://doi.org/10.1210/jc.20162935)

25 Handelsman DJ, Yeap B, Flicker L, Martin S, Wittert GA \& Ly LP. Agespecific population centiles for androgen status in men. European Journal of Endocrinology 2015173 809-817. (https://doi.org/10.1530/ EJE-15-0380)

26 Schnabel PG, Bagchus W, Lass H, Thomsen T \& Geurts TB. The effect of food composition on serum testosterone levels after oral administration of andriol testocaps. Clinical Endocrinology 200766 579-585. (https://doi.org/10.1111/j.1365-2265.2007.02781.x)

27 Gooren LJ. A ten-year safety study of the oral androgen testosterone undecanoate. Journal of Andrology 199415 212-215.

28 Lachance S, Dhingra O, Bernstein J, Gagnon S, Savard C, Pelletier N, Boudreau N \& Levesque A. Importance of measuring testosterone in enzyme-inhibited plasma for oral testosterone undecanoate androgen replacement therapy clinical trials. Future Science 20151 FSO55. (https://doi.org/10.4155/fso.15.55)

Received 7 June 2021

Revised version received 5 August 2021 Accepted 11 August 2021 